\title{
Drug delivery in female reproductive health
}

\author{
David R. Friend ${ }^{1}$
}

Published online: 11 September 2017

(C) Controlled Release Society 2017

\section{Editorial}

This theme issue has its origin in a previous theme issue on “Advances in Vaginal Drug Delivery" published in Drug Delivery and Translational Research in June 2011. That issue was based on a scientific session at the Controlled Release Society Annual Meeting held in Portland, OR, in July 2010. The goal for the current theme is to provide a more expansive look at drug delivery as it relates to female reproductive health.

A key aspect of female reproductive health remains focused on prevention of sexual transmission of HIV. Due to the inability to demonstrate successful clinical outcomes using pericoital (on-demand) vaginally administered products, there is increasing emphasis on the use of long-acting delivery systems. A key perceived advantage of long-acting dosage forms is that adherence will be substantially improved compared with that seen with pericoital products such as tenofovir vaginal gel [1]. Desai and coworkers [2] examined the field of long-acting systemic HIV pre-exposure prophylaxis. These long-acting systems fall into one of two general categories: injectable and implantable. One of the more interesting products under development relies on the extended release of cabotegravir (an integrase inhibitor). Due to potency, the ability to deliver antiviral drugs at effective levels will probably be no longer than 1 year and in some cases, no longer than 3 months.

Despite challenges observed with pericoital administration of vaginal gels, work continues on development of ondemand products for HIV and other STI prevention. Patel

David R. Friend

dfriend@evofem.com

1 Evofem Biosciences, Inc., San Diego, CA 92130, USA and Rohan have contributed an article covering on-demand microbicide products [3] including vaginal gels, films, and inserts (tablets). Woodrow and coworkers have provided their insights into use of electrospun fibers in female reproductive health [4]. Electrospun fibers have potential in prevention of acquisition of STIs including HIV, contraception, other reproductive tract infections, and in the field of multipurpose prevention technologies (MPTs).

Cervical cancer remains a serious health concern for women. Since the cervix is accessible through the vagina, localized delivery of chemotherapeutic drugs is reviewed by McConville and Major [5]. There are several vaginal dosage forms being investigated for treatment and reduction of recurrence of cervical cancer including inserts (tablets), rings, bioadhesive dosage forms, as well as cervical caps. Two other female reproductive conditions affecting many women worldwide are endometriosis and uterine fibroids. The use of drug delivery to address these two conditions has been reviewed [6]. Drug delivery for these conditions relies on marketed products (primarily contraceptives). In addition, newer approaches involving nanotechnology are under investigation.

Included in this issue are two articles (one an original article and another a short communication). The former describes research on a MPT product that can potentially release three antiviral agents and a contraceptive [7]. The latter article reports on the anti-HIV activity of MIV-150, a non-nucleoside reverse transcriptase inhibitor and zinc acetate [8].

\section{References}

1. Marrazzo JM, Ramjee G, Richardson BA, Gomez K, Mgodi N, Nair $\mathrm{G}$, et al. Tenofovir-based preexposure prophylaxis for HIV infection among African women. N Engl J Med. 2015;372(6):509-18. https:// doi.org/10.1056/NEJMoa1402269. 
2. Lykins WR, Luecke E, Johengen D, van der Straten A, Desai TA. Long acting systemic HIV pre-exposure prophylaxis: an examination of the field. Drug Delivery and Translational Research. 2017; https:// doi.org/10.1007/s13346-017-0391-6.

3. Patel SK, Rohan LC. On-demand microbicide products: design matters. Drug Delivery and Translational Research. 2017; https://doi. org/10.1007/s13346-017-0385-4.

4. Blakney AK, Jiang Y, Woodrow KA. Application of electrospun fibers for female reproductive health. Drug Delivery and Translational Research. 2017; https://doi.org/10.1007/s13346-0170386-3.

5. Major I, McConville C. Vaginal drug delivery for the localised treatment of cervical cancer. Drug Delivery and Translational Research. 2017; https://doi.org/10.1007/s13346-017-0395-2.
6. Friend DR. Drug delivery for the treatment of endometriosis and uterine fibroids. Drug Delivery and Translational Research. 2017; https://doi.org/10.1007/s13346-017-0423-2.

7. Derby N, Aravantinou M, Kenney J, Ugaonkar SR, Wesenberg A, Wilk J, et al. An intravaginal ring that releases three antiviral agents and a contraceptive blocks SHIV-RT infection, reduces HSV-2 shedding, and suppresses hormonal cycling in rhesus macaques. Drug Delivery and Translational Research. 2017; https://doi.org/10.1007/ s13346-017-0389-0.

8. Mizenina O, Hsu M, Jean-Pierre N, Aravantinou M, Levendosky K, Paglini G, et al. MIV-150 and zinc acetate combination provides potent and broad activity against HIV-1. Drug Delivery and Translational Research. 2017; https://doi.org/10.1007/s13346-0170421-4. 